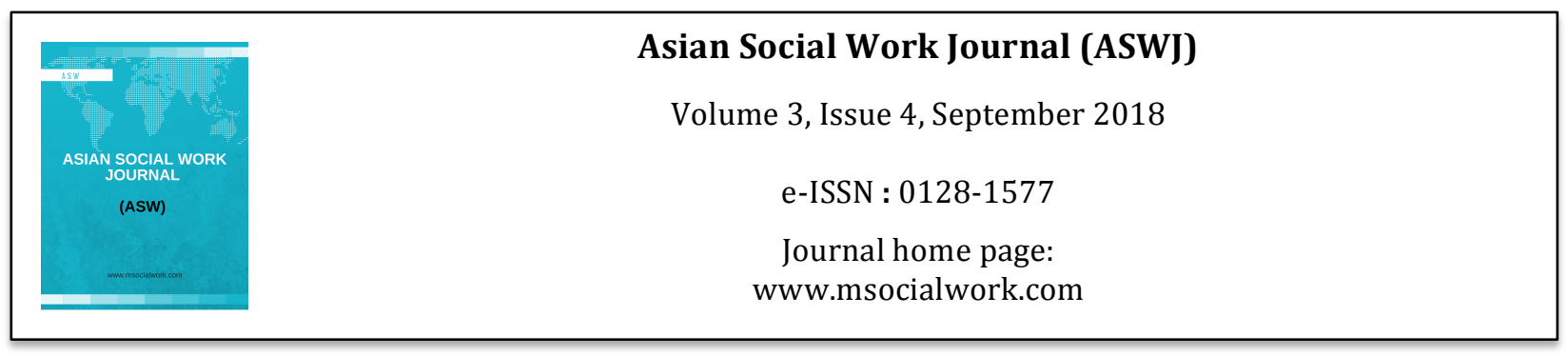

\title{
Equal Health Opportunity for Unskilled Migrant Workers within Limited National Healthcare Scheme in Thailand's Context
}

\author{
Wanwadee Poonpoksin 1 \\ ${ }^{1}$ Department of Social Work, Faculty of Social Administration, Thammasat University \\ Corrrespondence: Wanwadee Poonpoksin (nawadee@hotmail.com)
}

\begin{abstract}
Health is an important indicator of the population in every country, including migrant workers in destination countries, according to the provisions of international laws that govern health services without regard to the legal status of migrants. This article reviewed information from academic papers, research, and interviews with relevant personnel. The objective of this article is to point out information on health systems for migrants from the perspectives of both outsiders and insiders, which include research and data from interviews with the relevant health personnel in Thailand. The study indicated that academic papers published by foreigners see the Thai healthcare system as having a variety of problems in the exploitation of migrant workers, while Thai health personnel provides services without discrimination in all groups. In reality, Thai laws and national healthcare scheme require certain specific limited conditions for migrant workers for reasons of security, disease prevention, and control, including Thailand's struggle to deal with an influx of both legal and illegal workers into the country. Therefore, it is not easy to manage the healthcare scheme in order to increase coverage and equality for migrants and Thais alike. This study attempts to understand the development direction of the Thai health system as it moves into the future to provide coverage for all involved parties based on social capital and feasibility of action under the health policies of the developing country destination of Thailand.
\end{abstract}

Key words: equal health opportunity, national healthcare scheme, Thailand's context, unskilled migrant workers

\section{Introduction}

When talking about health, the most important access tool is health insurance, which is one of the key indicators of the population in all countries where the state provides support and has the duty of ensuring that all people have access to health insurance coverage. Thailand has been developing state health insurance for a long time. There are three major public health insurance schemes that protect people in different proportions, which are: (1) A health care system that protects five million civil servants and their families; (2) Providing coverage to over 10 million employees or insurers under the social security fund; and (3) The national health insurance fund that provides coverage for over 48 million people (Thailand Development Research Institute, 2013). However, health insurance is not only crucial for the citizens of the country but is also important for migrant populations and workers from other countries. The population of migrant workers has been increasing, due primarily to the fact that Thailand's economic and social development is better than the workers' countries of origin (Castles, 2000). Since 1987, migrant workers from three neighboring countries have been more likely to find jobs in Thailand than in their own countries. The Thai government must work to create health 
insurance coverage for these groups in accordance with the Universal Declaration of Human Rights and related other agreements at the international level.

Thailand has legislation to protect foreign migrant workers, and these laws have led to additional policy-making and work among relevant national agencies to increase the effectiveness of the protection of migrant workers.

\section{Understand the meaning and context of migrant workers in Thailand}

According to the Working Alien Act, B.E. 2551 (2008), the definition of an alien, in Section 5, refers to a person who is not of Thai nationality and also specifies a summary of the work of the immigrant under Section 7, that the work done by the alien takes into account three main issues, which are: (1) National security, (2) Occupational opportunities of Thais, and (3) Demand for alien workers as necessary for the development of the country. However, migrant workers in this article refer to registered unskilled migrants from Myanmar, Laos PDR, and Cambodia who are working in Thailand through the nationality verification process and memorandum of understanding on employment cooperation channels. The current situation is that there are many workers from these three neighboring countries coming to work as both legal and as undocumented workers. The report from the Ministry of the Interior states that the number of illegal migrant workers is more than that of the registered migrant labor workforce. For example, in 2010, unskilled migrant workers of these three nationalities numbered approximately 1 million documented immigrants and 1.4 million undocumented immigrants (United Nations Development Program, 2015). Similarly, the data from the Institute for Population and Social Research at Mahidol University (2012) found that the number of migrant workers and their dependents from these neighboring countries both regular and irregular was not significantly different, roughly 2.5 million. The International Labor Organization (ILO) focuses on the quality of life of workers, especially in the areas of health, education, and decent work, regardless of the legal status of migrant workers (Cernadas, LeVoy \& Keith, 2015; International Labor Organization, 2015). Thailand is evaluated by human rights organizations, particularly in its handling of health-related issues, and it was found that many documented workers were unable to access healthcare, even after they had paid for health insurance cards (Martin, 2007).

This article does not aim to defend the incompleteness of the Thai health service system or deny the lack of attention provided by the healthcare system to migrant workers in the country. The aim instead is to foster a common understanding of the situation by looking at the efforts of the Thai state to provide adequate health care to migrants from neighboring countries. Additionally, this article looks at attempts to ensure equality, including problems and obstacles that need to be resolved to develop and efficiently protect the long-term viability of the Thai health service system. This article is presented in three main sections, as follows: (1) Thai health insurance aimed at protecting foreign migrant workers, (2) Equal health opportunity for migrant workers versus the limitations of the national health care scheme, and (3) Challenges to the development of the Thai health insurance system to enhance the protection of migrant workers. Each section has the following details:

\section{Part 1: From health insurance of Thais to protect foreign migrant workers}

In general, access to health services is an essential dimension for all people, as stated by the International Labor Organization (2015), which reports that the compulsory migrant health insurance program in Thailand began in 2001. In the year 2003, the Ministry of Public Health began to conduct checks on health insurance for migrant workers who came from three neighboring countries.

The state health insurance for Thai citizens is part of the national health insurance fund and the social security fund, which are the health insurance types that are similar to those used for protecting migrant workers today. The design, access rights, and benefits are not very different from those available to Thai citizens. The Thai social security fund that protects Thai employees in the workplace as required by law is the same as that which protects registered migrant workers in Thailand, according to the social security office. Meanwhile, the national health insurance fund protects most Thais who do not 
receive social security benefits. It is similar in its protection of migrant workers who are not covered by the social security fund. Despite the similarity, there is still a clear difference. For example, health insurance for migrants is the responsibility of the Health Insurance Department at the Ministry of Public Health, while Thais are looked after by the National Health Security Office (NHSO). However, when considering the overall picture, the health insurance that protects migrant workers is similar to the health insurance that benefits Thais, with only minor differences based upon context. One difference between the health insurance coverage provided for Thais and migrant workers are the conditions under which each may access services. Both Thais and foreigners have access to (1) Health check-ups as required, (2) The purchase of a health insurance card at a fixed price after passing the health checkup, (3) Co-payment for all health services fee set at 30 baht (1 USD) per visit. However, foreigners under this plan must also adhere to rules number (4) Only one health care center can be used on the card, and (5) In the case of an emergency, the patient must be admitted to the health service center indicated on the card only; they cannot be admitted to other health services centers. If migrants do not meet the conditions of items 4 and 5, their health insurance will not be covered and it is their responsibility to pay all of their own expenses by themselves.

\section{Part 2: Equal health opportunity for migrant workers versus the limitations of the national healthcare scheme}

Although the Thai government is trying to ensure that migrant workers have equal access to health insurance, in reality, it is not so easy to distribute healthcare services fairly between citizens of the country and migrants. There are certain issues in Thailand society, as well as internationally, that need to be considered that involve social capital, Thai contexts, and the reasons for determining the conditions used to provide access to health care services for migrant workers.

\section{Health insurance for migrant workers: The social capital of the destination country must be considered}

The principles of the convention and declaration on the protection of health care services for migrant workers in all countries, including Thailand, regardless of the constraints and the various problems of the destination country, must be upheld to the best of that country's ability. This can, however, create pressure on the social capital of the country or the issues of health insurance the country still needs to develop for its citizens. The implementation of services of a destination country to protect migrants depends on its infrastructure and availability of resources, with international rules still serving to stimulate the development of host countries as well. The author believes that implementation is limited by social capital and its management by the Thai government. The foundations of the Thai health insurance system were originally designed and developed for Thai people and have evolved to include protection for various types of migrant workers who come to the country. The Thai government has made efforts to provide those migrant workers with equal and fair access to health care insurance and services as close to that of Thai citizens as possible.

\section{Protection for migrant workers in the context of Thai government health insurance}

To see the entire picture of health insurance for migrant workers in Thailand clearly, it is necessary to compare the health insurance benefits that Thai people receive from the state to those received by migrant workers, looking closely at the similarities as well as the differences between the two.

\section{Important conditions for Thai state management to provide access to health insurance for foreign migrant workers}

The author has reviewed and analyzed the conditions of state administrative procedures to determine the rules for obtaining and accessing health insurance by migrant workers, according to the following details: 


\section{The need for health status screening before accessing health insurance}

According to the process of registration as a licensed unskilled migrant worker, all migrant workers are required to undergo a medical examination by the Ministry of Public Health. If the results of the examination are acceptable according to the criteria, a worker will be able to purchase a health insurance card at a fixed price and for a specified period of time. After that, there is a process for obtaining a work permit and registering with an insurer in the social security fund for the type of work and the employment type required. Accordingly, migrant workers who have completed the various procedures correctly may not refuse the purchase of a health insurance card. Thai citizens, on the other hand, are entitled to a national health insurance card, which does not require a health checkup process to access the services it provides. The health checks are a benefit of the health promotion provided by the national health insurance fund that all Thai people are eligible for, regardless of which type of state health insurance they have.

Migrant workers have their health examined at the pre-registration stage. Workers from all three nations (Cambodia, Laos PDR, and Myanmar) receive different health screenings and surveillance services according to the risk of outbreaks and diseases that must be monitored from their country of origin. For example, workers from Myanmar have to take specific medicine and a blood test to combat lymphatic filariasis (elephantiasis), though migrants from Cambodia and Laos PDR do not.

\section{Setting health service center standards for migrant workers}

To ensure that migrant workers receive the same standard of health services as Thai citizens, the Ministry of Public Health has determined that participating hospitals must be accredited by one of the following criteria from the International Standards Organization (ISO) or the Hospital Accreditation (HA) (Ministry of Public Health, 2015). This standardization grants migrants access to the same health service centers as Thai citizens.

\section{The framing of national security through the definition of health conditions}

The Thai government continues to affect healthcare access for migrant workers by doing the following: (1) Establishment of health service centers for migrants to access health care. Although migrant workers must specify one center only from which they will receive care, if that work needs to be referred to another health center due to the severity of the disease or for a specific treatment, that care will be provided free of charge. (2) In case of emergency or accident, migrant workers must be admitted to the designated service center only and cannot use services in other units. If they choose to seek care in another health care center, they will be responsible for the costs of medical treatment by themselves. This is different from Thai citizens, who may use emergency services in any healthcare facility, with their designated healthcare center processing the expenses incurred.

\section{Health service centers consideration of the human rights of persons with legal status issues}

It cannot be denied that public health service centers in Thailand, especially those along the country's borders, are faced with financial debt difficulties incurred by providing services to people with legal status issues simply based upon their location next to neighboring, less affluent nations. These health service centers do not receive any extra financial support from the national health insurance fund. However, the budgetary shortfall does not diminish the attention to service provided by healthcare personnel. While the solution to this problem will be the efforts of local health administration officers to acquire much needed additional assistance, the humanitarian awareness of the Thai staff will continue to try to protect migrants with the same health service quality as they do for Thai citizens. 


\section{Part 3: Challenges to the development of the Thai health insurance system to enhance the protection of migrant workers}

The conditions that the Thai government has mentioned, both regarding a medical checkup for illness screening and the standardization of health service units for the use of health services by migrant workers, are benefits to the Thai government and migrant workers simultaneously. When considering this issue and others associated with it, the author believes the challenges of developing the health service system of Thailand are as follows:

\section{Identifying primary health care units on the health insurance card}

With the limitations of the service units listed in the health card of a migrant worker, only one secondary or tertiary healthcare unit is provided. This rule is different when compared to the service units specified in the health insurance card of Thai citizens, which consists of primary, secondary or tertiary units. In general, primary care units are located close to Thais or migrant worker's housing by geographical area. The dominant characteristics of primary care units are that they are close to the community, provide friendly services, are uncrowded, and have no complicated processes in their provision of services (unlike other levels of health centers). These criteria are necessary for migrant workers. Moreover, the use of a primary center will not cause migrants to feel stigmatized or discriminated against by other users (R. Khamsiri, personal communication, December 28, 2016). Therefore, the designation of a primary care unit on the health insurance card may make it more convenient for migrant workers to access healthcare.

\section{The fee is 30 baht per visit for all health services}

Use of services in the healthcare unit listed on the card costs 30 baht per visit for migrant workers, regardless of whether the service required is health promotion, disease prevention, medical treatment, or rehabilitation. Thai citizens, on the other hand, pay the 30 baht fee only for medical treatment and rehabilitation services. For migrants, this fee is linked to the regulation that only one specified health center may access a migrant worker as selected by that worker at the time of his or her registration for the plan; workers will be charged the actual cost for treatment if they choose to use services at other health centers. Such a designation reflects the conditions set forth for migrants as inferior to those of Thai citizens. In order to promote fairness, the Thai government could set a percentage co-payment for the migrants would be responsible, rather than requiring them to pay $100 \%$ of costs if they seek care at their non-designated healthcare center or at least by setting the co-payment as same as Thais.

\section{Free of charge health promotion and disease prevention services covering all target groups}

At present, migrant workers can receive the necessary vaccines for their children provided free of charge by primary health care centers, while some higher level health service units may charge 50 baht as a medical consultation fee, though the vaccines themselves are free of charge (W. Poonpoksin, personal communication, December 30, 2016). Such cases paint a picture of discrimination and inequality, the difference between the state care facilities available to Thai citizens and the health service centers where migrants receive care.

\section{Recommendation and Conclusion}

Thailand has yet to ratify the International Convention for the Protection of Migrant Workers' Rights and Family Members, a convention that is important to all countries and protects migrant workers regardless of race or legal status. However, Thai society cannot refuse to abide by the Declaration of Human Rights or other conventions that have already signed. In practice, countries have different interpretations of the basic health needs of migrant workers and the contexts of the health risks in their areas. The difference between these affects the conditions, limitations, and benefits of each country's health services. In Thailand, despite the creation of specific conditions and some limitations for 
migrant workers that differ from those of citizens of the country in gaining access to health care services, the nation needs to move forward in its pursuit of social and economic development without affecting national security among equal opportunity to access the fairness healthcare service as much as the Thai government can provide.

To sum up, the state is having a hard time managing the immigration process. Health agencies need to care for migrants, whether legal or illegal and to act in the best interest of the health of every person who stays in the country. At this point, the author wishes to suggest the idea that, if the state commits to the importance of the health of all people in the nation, then actions to reduce barriers or conditions to access healthcare services for migrants and others with legal status problems will yield positive results, not only for migrants or stateless people in terms of health, but also in the enormous value it will create in reducing the risk of illness among both migrants and Thai citizens in the country. This principle is an interesting and essential goal that leads to good health for all - not only the health of migrants but for all people to live in a healthy society. It is as important to provide positive health outcomes for migrant workers in a healthy society as it is for the citizens of the destination country.

\section{References}

Castles, S. (2000). International migration at the beginning of the twenty-first century: Global trends and issues. UNESCO.

Cernadas, P.C., LeVoy, M., \& Keith, L. (2015). Human rights indicators for migrants and their families. Global knowledge partnership on migration and development. Working paper.

Institute for Population and Social Research, Mahidol University. (2012). A situation analysis on health system strengthening for migrants in Thailand. Bangkok: Nattapon Plate.

International Labour Organization. (2015). Migrant workers' rights and welfare. ILO Country Office for Thailand, Asia Pacific Decent Work Decade, 2006-2015.

Khamsiri, R. Professional Nurse, Moo 12 Bangbuathong Health Center, Thailand. (2016, December 28). Interview.

Martin, P. (2007). The economic contribution of migrant workers to Thailand: Towards policy development. Bangkok: International Labor Organization.

Ministry of Public Health. (2015). Measures and guidelines for conducting health examinations and health insurance for aliens, March 30, 2015.

Poonpoksin, W. Professional Nurse, Bangtanai Health Center, Thailand. (2016, December 30). Interview.

Thai government. (2008). Working of Alien Act of Thailand, B.E. 2551 (A.D. 2008).

Thailand Development Research Institute. (2013). Development of the healthcare system project. Research report.

United Nations. (1948). Universal declaration of human rights. Retrieved from http://www.un.org/en/udhrbook/\#1

United Nations Development Program. (2015). The right to health: Right to health for low-skilled labor migrants in ASEAN countries. Bangkok: United Nations. 